\title{
APPLICATIONS OF NON-LINEAR FREQUENCY RESPONSE FOR INVESTIGATION OF ADSORPTION SYSTEMS
}

\author{
Menka Petkovska \\ Department of Chemical Engineering, Faculty of Technology and Metallurgy, University of Belgrade, \\ Belgrade, Serbia \\ menka@tmf.bg.ac.yu
}

\begin{abstract}
Two main directions of application of nonlinear frequency response and the concept of higher order frequency response functions (FRFs) in investigation of adsorption systems are presented, one for development of novel methods for investigation of equilibrium and kinetics of adsorption systems, and the other for fast estimation of periodic steady-states of cyclic adsorption processes. The main advantages of the nonlinear FR methods for estimation of adsorption equilibrium and kinetics are: (1) It is possible to discriminate between different kinetic mechanisms and to select the correct one from the shapes of the second and higher order FRFs. (2) Both equilibrium and kinetic parameters can be estimated from the FRFs. Different experimental arrangements are presented. Estimation of periodic steady-states of cyclic adsorption processes is illustrated on the example of periodic operation of an adsorption column with modulation of the inlet concentration and the column temperature.
\end{abstract}

Key words: frequency response functions; adsorption; kinetics; equilibrium; periodic operation

\section{ПРИМЕНА НА НЕЛИНЕАРЕН ФРЕКВЕНЦИСКИ ОДЗИВ ЗА ИСПИТУВАЊЕ НА АТСОРПЦИОНИТЕ СИСТЕМИ}

Во трудот се презентирани два главни правца на примената на нелинеарниот фреквенциски одзив и концептот на фреквенциските преносни функции (FPF) од повисок ред за испитување на атсорпционите системи. Едниот правец се однесува на развој на нови експериментални методи за испитување на рамнотежата и кинетиката на атсорпционите системи, додека другиот се однесува на развој на пресметковен метод за приближно определување на стационарната состојба кај цикличните атсорпциони процеси. Најважните предности на методот за испитување на рамнотежата и кинетиката на атсорпција засновани на нелинеарниот фреквенциски одзив се: (1) можноста за идентификација на вистински кинетички механизам и соодветен математички модел врз основа на обликот на втората и повисоките FPF и (2) можноста за определување на рамнотежните и кинетичките параметри на моделот од истите експериментални податоци. Во трудот се прикажани различни технички решенија на експерименталните системи за примена на нелинеарните фреквенциски методи. Од друга страна, методот за брзо приближно пресметување на периодичната стационарна состојба на цикличните атсорпциони процеси е развиена со цел да го замени комплицираното и долготрајно нумеричко решавање на математичките модели за овие процеси. Овој метод е илустриран со примери на периодична работа на атсорпциона колона со периодична промена на влезната концентрација и температурата на колоната.

Клучни зборови: фреквенциски преносни функции; атсорпција; кинетика; рамнотежа; периодични операции

\section{INTRODUCTION}

Nonlinear frequency response is a quasistationary response of a nonlinear system to a periodic (sinusoidal or cosinusoidal) input, around a steady-state. One of the most convenient tools for treating nonlinear frequency responses is the concept of higher order frequency response functions [1], which is based on Volterra series and generalized Fourier transform. This concept is very con- 
venient for analyzing weakly nonlinear systems. The basics for its application lay in the facts that [1]:

- Frequency response (FR) of a nonlinear system contains, in addition to the first (basic) harmonic, a DC component and an indefinite number of higher harmonics (Fig. 1, equation (1)):

$$
\begin{aligned}
& x=x_{S}+A \cos (\omega t) \Rightarrow \\
& y=y_{S}+y_{D C}+B_{I} \cos \left(\omega t+\varphi_{I}\right)+ \\
& +B_{I I} \cos \left(2 \omega t+\varphi_{I I}\right)+B_{I I I} \cos \left(3 \omega t+\varphi_{I I I}\right)+\cdots
\end{aligned}
$$

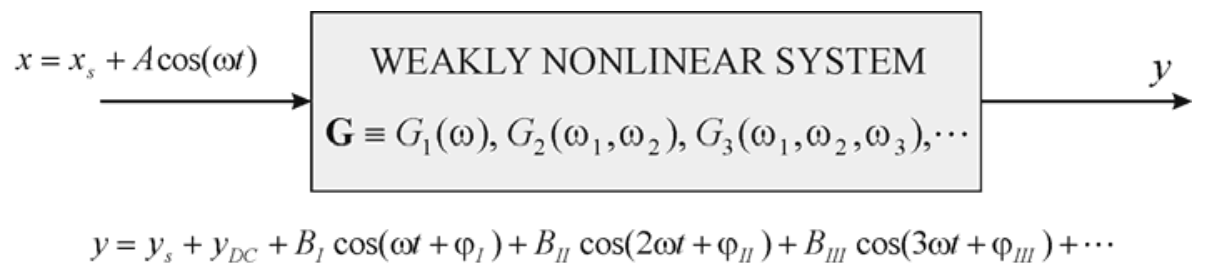

Fig. 1. Schematic representation of frequency response of a weakly nonlinear system

- A model of a weakly nonlinear system can be replaced by an indefinite sequence of linear models of different orders. In the frequency domain these linear models are defined as frequency response functions (FRFs) of different orders $\left(G_{1}(\omega), G_{2}\left(\omega_{1}, \omega_{2}\right), G_{3}\left(\omega_{1}, \omega_{2}, \omega_{3}\right)\right.$ in Fig. 1), which are directly related to different harmonics of the FR: the first order FRF $G_{1}(\omega)$ corresponds to the most significant term of the first harmonic:

$$
\begin{aligned}
& B_{I} \cos \left(\omega t+\varphi_{I}\right)= \\
& \left\{(A / 2) G_{1}(\omega)+3(A / 2)^{3} G_{3}(\omega, \omega,-\omega)+\cdots\right\} e^{j \omega t} \\
& +\left\{(A / 2) G_{1}(-\omega)+3(A / 2)^{3} G_{3}(\omega,-\omega,-\omega)+\cdots\right\} e^{-j \omega t}
\end{aligned}
$$

the second order FRFs $G_{2}(\omega, \omega)$ and $G_{2}(\omega,-\omega)$ correspond to the most significant terms of the second harmonic and the DC component:

$$
\begin{aligned}
& B_{I I} \cos \left(2 \omega t+\varphi_{I I}\right)= \\
& \left\{(A / 2)^{2} G_{2}(\omega, \omega)+4(A / 2)^{4} G_{4}(\omega, \omega, \omega,-\omega)+\cdots\right\} e^{2 j \omega t} \\
& +\left\{(A / 2)^{2} G_{2}(-\omega,-\omega)+4(A / 2)^{4} G_{4}(\omega,-\omega,-\omega,-\omega)+\cdots\right\} e^{-2 j \omega t}
\end{aligned}
$$

$$
\begin{aligned}
y_{D C}= & 2(A / 2)^{2} G_{2}(\omega,-\omega)+ \\
& +6(A / 2)^{4} G_{4}(\omega, \omega,-\omega,-\omega)+\cdots
\end{aligned}
$$

and so on.

Accordingly, the FRFs of different orders can be estimated from different harmonics of the FR.
Being weakly nonlinear, adsorption systems are good candidates for investigation based on this concept. Up until now, our investigations of adsorption systems by nonlinear FR have been organized into two main directions:

- Development of experimental techniques for investigation of adsorption equilibrium and kinetics [2].

- Development of a computational technique for fast approximate estimation of periodic steady states of cyclic adsorption processes [3].

\section{NONLINEAR FR METHODS FOR INVESTIGATION OF ADSORPTION EQUILIBRIUM AND KINETICS}

Adsorption systems generally involve a number of interacting phenomena and processes, with different complex, and often not well known, kinetic mechanisms. For their proper design, the knowledge of both equilibrium and kinetics is essential.

Application of the nonlinear FR for investigation of adsorption equilibrium kinetics and dynamics is based on the following facts which make it potentially advantageous over other methedsNonlinear FR results in a set of FRFs, which contain different information. In a number of cases, the second and higher order FRFs corresponding to different kinetic mechanisms differ in shape, which enables reliable discrimination be- 
tween different kinetic mechanisms and identification of the correct one.

- The obtained set of FRFs can be used for estimation of both kinetic and equilibrium parameters of the identified model, including those defining the system nonlinearity.

The nonlinear FR analysis can be performed using different experimental arrangements. In our investigations we have developed several techniques, based on the following arrangements:

- An ideally mixed adsorber with a periodic change of the reservoir volume or inlet flow-rate;

- A chromatographic column with a periodic change of the inlet concentration;

- A zero-length column (ZLC) with a periodic change of the inlet concentration;

- A two-reservoir system divided by a membrane, with a periodic change introduced to one of the reservoirs.

Some of these techniques have been developed only theoretically, while others have also been tested experimentally.

For the sake of simplicity, in this manuscript we will limit our analysis only to isothermal cases, although nonlinear FRFs of some nonlisothermal cases have also been derived and analyzed [4].

\subsection{Particle FRFs}

The usual way of using the FR technique for investigation of adsorption kinetics is to analyze the response of the adsorber. Nevertheless, the final aim of the FR investigation is to reveal the kinetic mechanism and to obtain the equilibrium and kinetic parameters of the adsorption process. In practice, this aim is reduced to identification of the best mathematical model on the particle level. Accordingly, we recognize the particle as a subsystem of the adsorber (Figure 2) and we define two sets of FRFs, one representing the model on the adsorber scale (in this manuscript denoted as $\left.G_{1}(\omega), G_{2}\left(\omega_{1}, \omega_{2}\right), G_{3}\left(\omega_{1}, \omega_{2}, \omega_{3}\right) \ldots\right)$, and the other on the particle scale (denoted as $F_{1}(\omega), F_{2}\left(\omega_{1}, \omega_{2}\right)$, $\left.F_{3}\left(\omega_{1}, \omega_{2}, \omega_{3}\right) \ldots\right)$ [5]. The particle FRFs depend only on the kinetic mechanism, while the adsorber ones depend on the adsorber type as well.

For isothermal cases, the mathematical model of the particle relates the adsorbate concentration in the particle $Q$ (the particle output) to the concentration in the fluid phase $C$ surrounding the particle (the particle input).

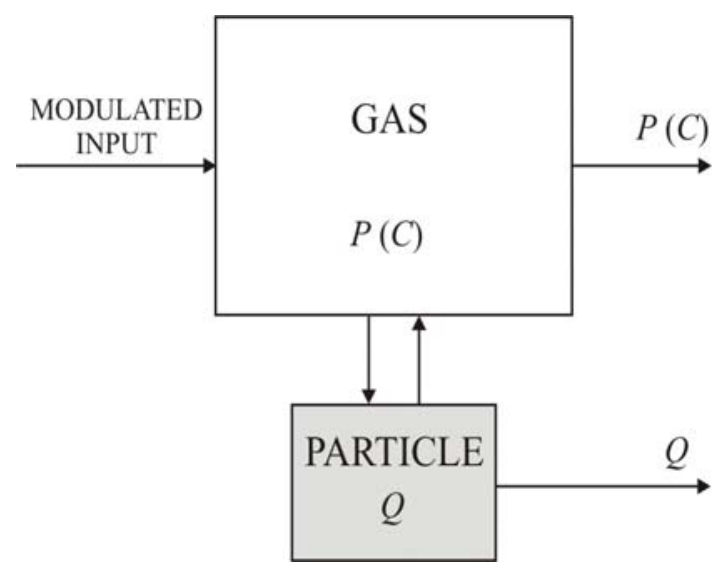

Fig. 2. Schematic representation of an adsorber-adsorber and particle inputs and outputs

1) Experimental FR measurements by modulating a chosen adsorber input periodically around a chosen steady-state.

2) Harmonic analysis of the adsorber output signals.

3) Estimation of the adsorber FRFs, based on experiments performed with 2 or 3 input amplitudes.

4) Calculation of the particle FRFs from the adsorber ones, based on the adsorber model.

5) Identification of the kinetic model by comparing the shapes of the estimated particle FRFs with theoretically derived FRFs corresponding to different kinetic mechanisms.

6) Estimation of the equilibrium and kinetic parameters of the identified model.

\subsubsection{Model discrimination}

A very important step of the described procedure is identification of the correct kinetic model. It is based on model discrimination which is performed by comparing the shapes of the particle FRFs obtained from experimental data with theoretically derived FRFs corresponding to different models, i.e. kinetic mechanisms. It has been shown that the second order particle FRFs offer enough information for model discrimination $[6,7,8]$. Here are some characteristic examples of model discrimination based on the second order particle FRFs. 
Example 1: Discrimination between isothermal micropore and pore-surface diffusion mechanisms

In a number of cases, the overall rate of the adsorption process is governed by a Fickian diffusion process, either on the micro-particle level (by micropore diffusion), or on the macro-particle level (by pore-surface diffusion mechanism).

Investigations by linear FR resulted in identical shapes of the FR-characteristic curves for the micropore and pore-surface diffusion mechanisms. Nevertheless, the second order FRFs corresponding to the two mechanisms have different shapes, as illustrated in Fig. 3, in which the FRFs for micropore diffusion are shown as lines, and the FRFs for pore-surface diffusion as lines with symbols. The FRFs presented in Fig. 3 correspond to models with constant diffusion coefficients, plane geometry, and favourable adsorption isotherm. Standard Bode plot representation is used (amplitudes vs. frequency are plotted in log-log, and phases vs. frequency in semi-log diagrams).

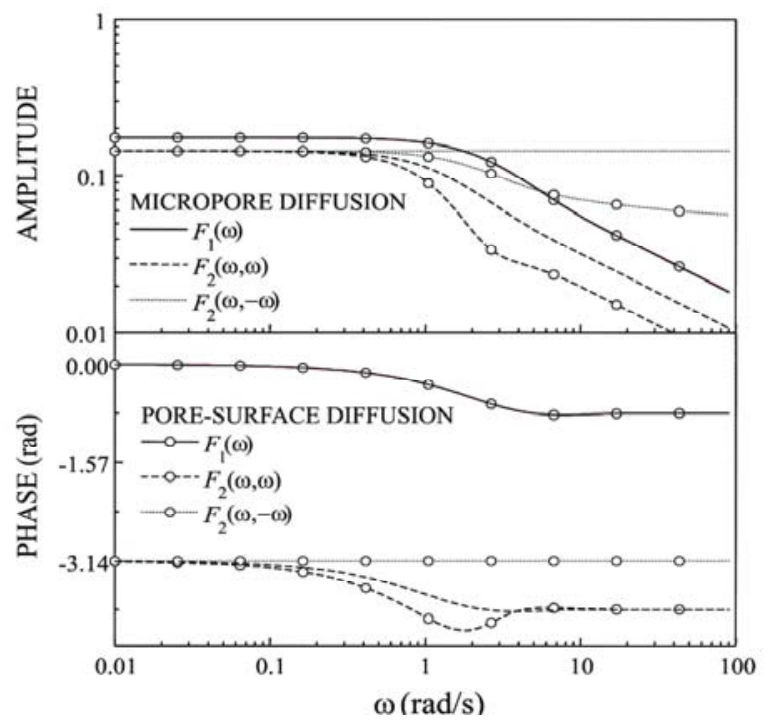

Fig. 3. First and second order FRFs for micropore and pore-surface diffusion mechanisms

Example 2: Discrimination among three models used to describe bimodal characteristic curves

A very characteristic example of the inability of the classical linear frequency response method to identify the correct kinetic mechanism is adsorption of some substances (e.g. p-xylene, 2butane, propane or $n$-hexane) on silicalite-1.

The linear FR resulted in bimodal FR characteristic functions [9], such as those shown in Fig. 4. These characteristic functions fitted equally well to three different kinetic models: two inde- pendent isothermal diffusion processes (Model 1), an isothermal diffusion-rearrangement process (Model 2) and a nonisothermal micropore diffusion process (Model 3) [9].

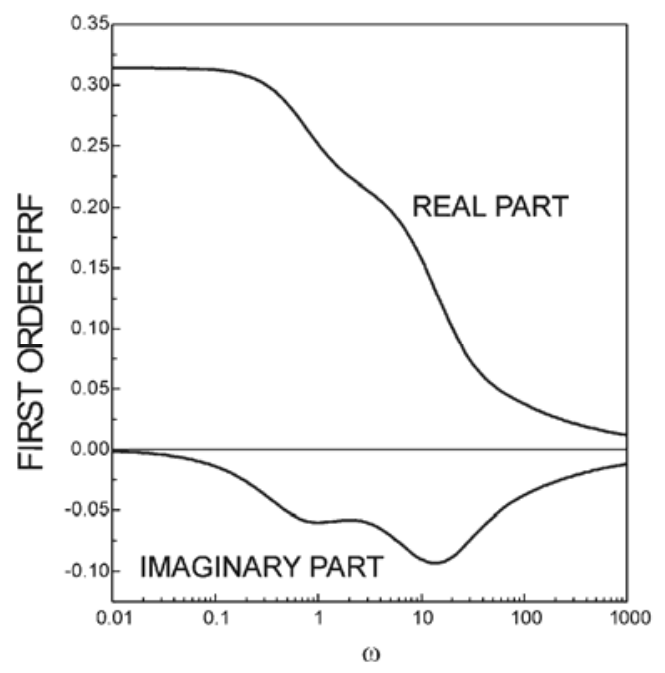

Fig. 4. An example of bimodal characteristic curves

Our analysis, based on the nonlinear FR and the higher order FRFs corresponding to those three models, showed that the second order FRFs can be used for discrimination among these three mechanisms. The asymmetrical second order FRFs $F_{2}(\omega,-\omega)$, corresponding to the three models, are shown in Fig. 5. The obvious differences in their shape give enough information for identification of the correct model.

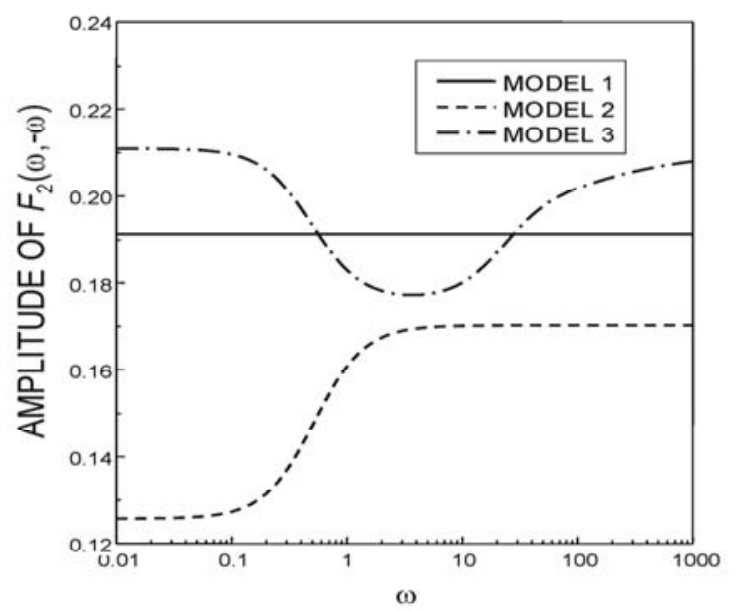

Fig. 5. Amplitude functions of $F_{2}(\omega,-\omega)$ for models 1,2 and 3

Example 3: Isothermal adsorption on bidispersed sorbents - models of different complexity

In a number of cases, the adsorbent material is produced in the form of granules or pellets, 
composed of a large number of microparticles. Complex kinetic mechanisms are characteristic for these so-called bidispersed adsorbents. In such systems, diffusion on both macro-particle (pellet) and micro-particle scale usually influences the overall adsorption rate. Often, the adsorption/desorption rate at the micropore mouth and/or the film mass transfer at the macro-particle surface also have to be taken into account. In case of significant heat effects, the heat generation and transfer have to be taken into account, as well.

Depending on the kinetic parameters in a particular system, the overall rate of the adsorption process can be defined by a single mechanism, or by combination of two, three or all four mechanisms. A detailed analysis of this problem is given in [10].

An overview of the characteristic behaviour of the first and second order FRFs for mechanisms of different complexity is given in Table 1 . The meaning of the letters describing the mechanisms is as follows: $\mathrm{M}$ - micropore diffusion, $\mathrm{P}$ - pore diffusion, $\mathrm{L}$ - Langmuir kinetics, and $\mathrm{F}$ - film resistance. The results presented in Table 1 show that the mechanism can be identified from the second order FRFs, i.e. from their high-frequency asymptotic behaviour. The limiting values shown in Table 1 correspond to the case of a favourable isotherm. For unfavourable isotherms, the phases of $F_{2}(\omega, \omega)$ and $F_{2}(\omega,-\omega)$ are shifted by $+\pi$, in comparison to the ones given in Table 1 .

Table 1

Summary of the high-frequency behaviour of the first and second order FRFs for isothermal kinetic mechanisms of different complexity

\begin{tabular}{l|ccc|cc}
\hline \hline \multirow{2}{*}{ Mechanism } & \multicolumn{3}{|c|}{ Slope of the amplitude for $\omega \rightarrow \infty$} & \multicolumn{2}{|c}{ Phase for $\omega \rightarrow \infty$} \\
\hline $\mathrm{M}$ & $F_{1}(\omega)$ & $F_{2}(\omega, \omega)$ & $F_{2}(\omega,-\omega)$ & $F_{1}(\omega)$ & $F(\omega, \omega)$ \\
\hline $\mathrm{P}$ & -0.5 & -0.5 & 0 & $-\pi / 4$ & $-5 \pi / 4$ \\
$\mathrm{~L}$ & -0.5 & -0.5 & -0.5 & $-\pi / 4$ & $-5 \pi / 4$ \\
$\mathrm{~F}$ & -1.0 & -2.0 & -2.0 & $-\pi / 2$ & $-2 \pi$ \\
$\mathrm{M}+\mathrm{P}$ & -1.0 & -3.0 & -2.0 & $-\pi / 2$ & $-5 \pi / 2$ \\
$\mathrm{M}+\mathrm{P}+\mathrm{L}$ & -0.5 & -1.0 & -0.5 & $-\pi / 4$ & $-3 \pi / 2$ \\
$\mathrm{M}+\mathrm{P}+\mathrm{F}$ & -0.5 & -2.0 & -1.0 & $-\pi / 4$ & $-2 \pi$ \\
$\mathrm{M}+\mathrm{P}+\mathrm{L}+\mathrm{F}$ & -1.0 & -2.5 & -1.5 & $-\pi / 2$ & $-9 \pi / 4$ \\
\hline \hline
\end{tabular}

*The meaning of the letters describing the mechanisms is as follows: $\mathrm{M}$ - micropore diffusion, $\mathrm{P}$ - pore diffusion, $\mathrm{L}$ - Langmuir kinetics and $\mathrm{F}-$ film resistance.

\subsubsection{Estimation of model parameters}

Once the correct model of adsorption has been identified, the FRFs determined from experimental FR data can be used for estimation of the model parameters. In principle, both the equilibrium and kinetic parameters can be estimated from the FRFs.

\section{Estimation of equilibrium parameters}

For analysis in the frequency domain it is most convenient to represent the adsorption isotherm in the Taylor series form:

$$
q=\Phi(c)=\widetilde{a} c+\widetilde{b} c^{2}+\widetilde{c} c^{3}+\cdots
$$

where $c$ and $q$ are nondimensional concentrations in the fluid and solid phase, respectively, defined as relative deviations from their steady-state values $C_{s}$ and $Q_{s}$, and the Taylor series coefficients $\widetilde{a}, \widetilde{b}, \widetilde{c}, \ldots$ are proportional to the nondimensional derivatives of the adsorption isotherm around the investigated steady-state. These coefficients are directly related to the low-frequency asymptotes of the particle FRFs, in the following way:

- For isothermal adsorption in nonporous particles:

$$
\begin{aligned}
& \tilde{a}=\lim _{\omega \rightarrow 0} F_{1}(\omega), \\
& \tilde{b}=\lim _{\omega \rightarrow 0} F_{2}(\omega, \omega), \\
& \tilde{c}=\lim _{\omega \rightarrow 0} F_{3}(\omega, \omega, \omega), \cdots
\end{aligned}
$$

- For isothermal adsorption in porous particles of porosity $\varepsilon_{\mathrm{p}}$ :

$$
\begin{aligned}
& \lim _{\omega \rightarrow 0} F_{1}(\omega)=\frac{\varepsilon_{p} C_{s}+\left(1-\varepsilon_{p}\right) \widetilde{a} Q_{s}}{\varepsilon_{p} C_{s}+\left(1-\varepsilon_{p}\right) Q_{s}}=\widetilde{a}_{e f f} \\
& \lim _{\omega \rightarrow 0} F_{2}(\omega, \omega)=\frac{\left(1-\varepsilon_{p}\right) \tilde{b} Q_{s}}{\varepsilon_{p} C_{s}+\left(1-\varepsilon_{p}\right) Q_{s}}=\widetilde{b}_{e f f} \\
& \lim _{\omega \rightarrow 0} F_{3}(\omega, \omega, \omega)=\frac{\left(1-\varepsilon_{p}\right) \widetilde{c} Q_{s}}{\varepsilon_{p} C_{s}+\left(1-\varepsilon_{p}\right) Q_{s}}=\widetilde{c}_{e f f}, \cdots
\end{aligned}
$$

In this way, theoretically any first $n$ derivatives of the adsorption isotherm corresponding to the chosen steady-state concentration can be estimated, from the first $n$ FRFs obtained from the nonlinear FR experiments. Estimation of these de- 
rivatives for several steady-state concentrations usually gives enough information for constructing a complete adsorption isotherm $[11,12]$. It is important to note that the sign of the second isotherm derivative $\tilde{b}$ directly defines the shape of the isotherm in that steady-state point (favourable or unfavourable). Using this fact, inflection points of the adsorption isotherm can be easily delineated.

\section{Estimation of kinetic parameters}

For simple kinetic mechanisms, the kinetic parameters can also be estimated readily, from the locus of the minimum of the imaginary part of the first order FRF $F_{1}(\omega)$ [13].

For an adsorption process governed by a single Fickian diffusion process, the time constant is defined as the ratio $\tau=L^{2} / D$, where $L$ is the characteristic half dimension and $D$ the diffusion coefficient [13]. Accordingly, the time constants for the micropore and pore surface diffusion models would be:

$$
\tau_{M}=\frac{R_{\mu}^{2}}{D_{\mu}}, \quad \tau_{P S}=\frac{R^{2}}{D_{\text {eff }}}
$$

respectively, where

$$
D_{e f f}=\frac{\left(1-\varepsilon_{p}\right) D_{s} \tilde{a}_{p} Q_{s}+\varepsilon_{p} D_{p} C_{s}}{\left(1-\varepsilon_{p}\right) \tilde{a}_{p} Q_{s}+\varepsilon_{p} C_{s}}
$$

is the so-called effective, or apparent diffusion coefficient, $D_{\mu}, D_{s}$ and $D_{p}$ are micropore, surface and pore diffusion coefficients, respectively, while $R_{\mu}$ and $R$ are the microparticle and particle halfdimensions.

The negative imaginary parts of the $F_{1}(\omega)$ functions, corresponding to a single diffusion mechanism and to three different geometries (plane, cylindrical and spherical) are shown in Fig. 6.

The maximums of these curves correspond to $\omega \tau=2.5492,6.3504$ and 11.5630 for plane, cylindrical and spherical geometry, respectively.

Using these results, the time constant of the diffusion process is obtained from the locus of the maximum of the $-\operatorname{Imag}\left(F_{1}(\omega)\right)$ curve and the knowledge of the microparticle or macroparticle geometry. The corresponding diffusion coefficient is obtained as the ratio of the square of the microparticle or macro-particle half-dimension and the time constant: $D=L^{2} / \tau$.

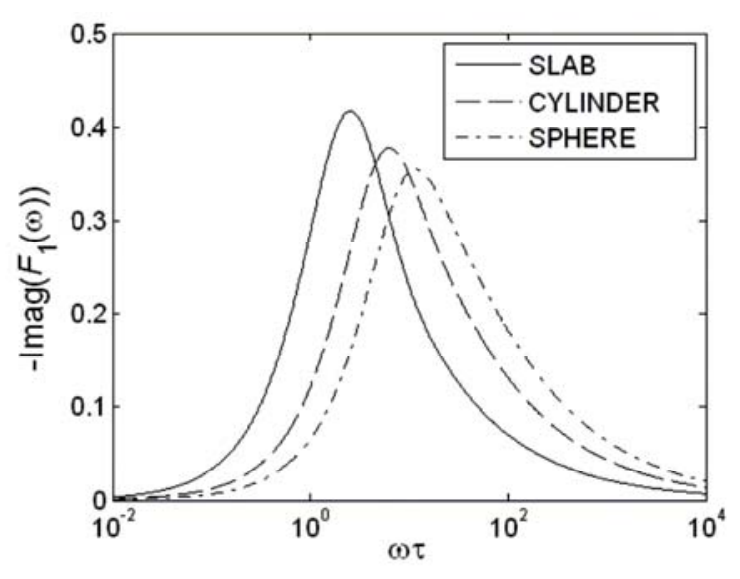

Fig. 6. The negative imaginary part of $F_{1}(\omega)$ for diffusion models

The FRFs for isothermal micropore and poresurface diffusion models, shown in Fig. 3, were obtained for constant diffusion coefficients. If this assumption is not met, i.e. if concentration dependence of the diffusion coefficient has to be taken into account, the value estimated from the maximum of the $-\operatorname{Imag}\left(F_{1}(\omega)\right)$ curve is the diffusion coefficient corresponding to the steady-state concentration.

The case of micropore diffusion with variable diffusivity has also been investigated [4]. If the concentration dependence of the micropore diffusion coefficient is expressed in the Taylor series form:

$$
D_{\mu}=\Xi(q)=D_{\mu, s}+D_{\mu}^{(1)} q+D_{\mu}^{(2)} q^{2}+\cdots
$$

the expansion coefficients can also be estimated from the higher order FRFs. E.g., it can be shown that [4]:

$$
\lim _{\omega \rightarrow \infty} F_{2}(\omega,-\omega)=\widetilde{b}+\frac{D_{\mu}^{(1)} \widetilde{a}^{2}}{2 D_{\mu, s}}
$$

For the pore-surface diffusion model, only the effective diffusion coefficient can be estimated from the first order function, and not the pore and surface diffusion coefficients, separately. Nevertheless, the high-frequency asymptotic values of the second order FRF $F_{2}(\omega,-\omega)$ :

$$
\lim _{\omega \rightarrow \infty} F_{2}(\omega,-\omega)=\widetilde{b}_{\text {eff }} \frac{D_{s}}{D_{\text {eff }}}
$$

can be used for estimation of separate values of the pore and surface diffusion coefficients $D_{p}$ and $D_{s}$. This would not be possible by standard (linear) methods. 
For complex kinetic mechanisms, estimation of the kinetic parameters becomes much more difficult and nonlinear least-square methods have to be used.

\subsection{Different experimental configurations}

\subsubsection{Ideally mixed reservoir-type adsorber}

The FR experiments are usually performed in an ideally mixed reservoir-type adsorber containing solid adsorbent and gaseous adsorbate, in which periodic changes of pressure and adsorbed quantity are produced by forced periodic modulation of some input variable. The experiments can be performed in a batch reservoir with volume modulation (Schematically shown in Fig. 7), or in a continuous flow reservoir with inlet flow-rate modulation [14]. In both cases, the adsorber output measured is the pressure in the reservoir.

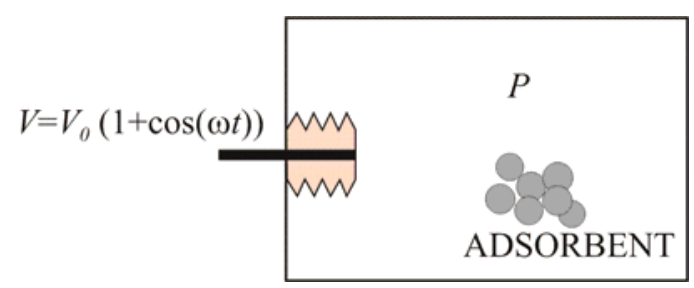

Fig. 7. Schematic representation of a batch ideally mixed reservoir-type adsorber with volume variation

For both cases, the mathematical model of the reservoir-type adsorber with adsorption of a pure gas can be defined by the following common equation:

$$
\frac{d}{d t}((1+v)(1+c))+\beta \frac{d\langle q\rangle}{d t}=\gamma n_{i}-\gamma c
$$

where:

$$
\beta=\frac{V_{p}}{V_{s}} \frac{Q_{s}}{C_{S}}, \quad \gamma=\frac{N_{s}}{V_{S} C_{S}} \text { and }<q>=\mathbf{F}(c)
$$

The input and output variables, volume $v$, gas concentration $c$, loading $q$ and inlet molar flowrate $n_{i}$, are defined as nondimensional variations around their steady-state values $V_{s}, C_{s}, Q_{s}$ and $N_{s}$, respectively. The concentration in the solid particle is usually nonuniform, so its average value $\langle q\rangle$ is used in equation (13).

For a batch adsorber with volume modulation $\gamma=0$, while for a flow adsorber with inlet molar flow-rate modulation and constant volume, $v=0$.
Based on the appropriate adsorber model, the following adsorber vs. particle FRFs relations were obtained:

- For a batch reservoir with volume modulation:

$$
G_{1}(\omega)=-\frac{1}{1+\beta F_{1}(\omega)}
$$

$$
G_{2}(\omega, \omega)=-\frac{G_{1}(\omega)\left(1+\beta G_{1}(\omega) F_{2}(\omega, \omega)\right)}{1+\beta F_{1}(2 \omega)}
$$

$G_{2}(\omega,-\omega)=$

$$
-\frac{\left.\left(G_{1}(\omega)+G_{1}(-\omega)\right) / 2+2 \beta G_{1}(\omega) G_{1}(-\omega) F_{2}(\omega,-\omega)\right)}{1+\beta F_{1}(0)}
$$

etc.

- For a flow reservoir with inlet molar flowrate modulation:

$$
\begin{gathered}
G_{1}(\omega)=\frac{\gamma}{\gamma+j \omega\left(1+\beta F_{1}(\omega)\right)} \\
G_{2}(\omega, \omega)=-\frac{2 \beta j \omega G_{1}^{2}(\omega) F_{2}(\omega, \omega)}{\gamma+2 j \omega\left(1+\beta F_{1}(2 \omega)\right)} \\
G_{2}(\omega,-\omega)=0, \text { etc. }
\end{gathered}
$$

The last result is very important, because as its consequence, it is not possible to estimate the asymmetrical second order particle FRF $F_{2}(\omega,-\omega)$ from experiments in the flow system. As shown in Section 2.1.1., this function can be very useful for mechanism discrimination.

\subsubsection{Chromatographic system}

The assumption of perfect mixing in a reservoir-type adsorber is usually not acceptable for adsorptions from liquid phase. That was a reason for developing a method based on nonlinear FR of a chromatographic column, for which the fluid flow is much better defined. The frequency response functions of a chromatographic column were defined in such a way to relate the nondimensional outlet concentration from the column $c_{o}$ to the periodic change of the inlet concentration $c_{i}$, for constant flow-rate of the fluid phase [11].

\section{Chromatographic column with single adsorbing component}

The FRFs of a chromatographic column with a single adsorbing component were derived start- 
ing from the commonly used dispersion model [15], written in its nondimensional form:

$$
\begin{aligned}
& \frac{\partial c}{\partial \tau}+\frac{1-\varepsilon}{\varepsilon} \frac{Q_{s}}{C_{s}} \frac{\partial\langle q\rangle}{\partial \tau}+\frac{\partial c}{\partial x}=\frac{1}{2 N} \frac{\partial^{2} c}{\partial x^{2}}, \\
& \langle q\rangle=\mathbf{F}(c)
\end{aligned}
$$

with the well known Dankwertz boundary conditions:

$$
\begin{aligned}
& x=0: c(0, \tau)=c_{i}(\tau)+\left.\frac{1}{2 N} \frac{\partial c}{\partial x}\right|_{x=0}, \\
& x=1:\left.\frac{\partial c}{\partial x}\right|_{x=1}=0
\end{aligned}
$$

Typical Bode plots showing the first, second and third order FRFs of a chromatographic column are shown in Fig. 8. These FRFs relate the changes of the nondimensional outlet and inlet concentrations, defined as relative deviations from their steady-state values. The functions shown in Fig 8 correspond to a favourable isotherm and local equilibrium between the phases in each point of the column.

Contrary to the cases of the reservoir-type adsorbers, estimation of the particle FRFs from those in the column is not easy. As an illustration, we give the expression for the first order FRF:

$$
G_{1}(\omega)=\frac{2 N\left(\lambda_{2}-\lambda_{1}\right) e^{\lambda_{2}}}{2 N\left(\lambda_{2} e^{\lambda_{2}-\lambda_{1}}-\lambda_{1}\right)+\lambda_{1} \lambda_{2}\left(1-e^{\lambda_{2}-\lambda_{1}}\right)}
$$

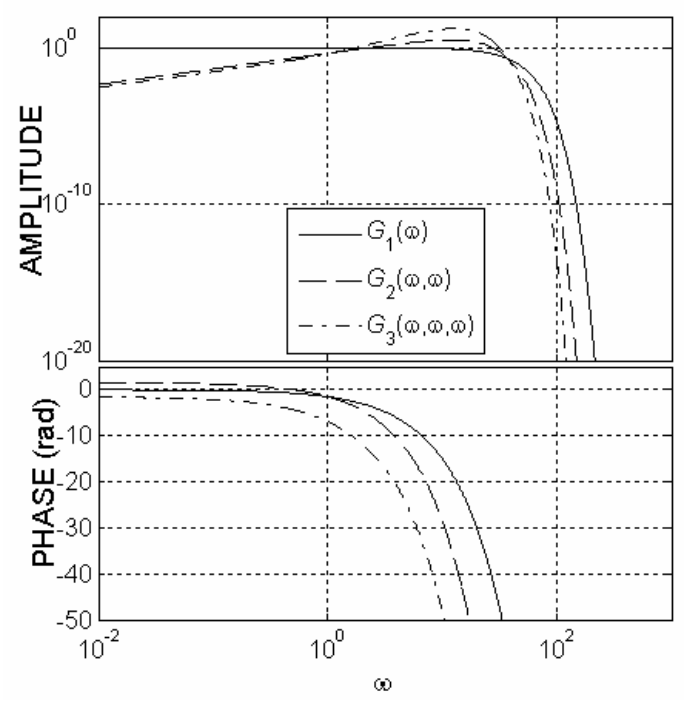

In equation (23) $\lambda_{1}$ and $\lambda_{2}$ are solutions of the corresponding characteristic equation which are related to the particle first order FRF $F_{1}(\omega)$, in the following way:

$$
\lambda_{1,2}(\omega)=N \pm \sqrt{N^{2}+2 N\left(1+F_{1}(\omega) \frac{1-\varepsilon}{\varepsilon} \frac{Q_{S}}{C_{S}}\right) j \omega}
$$

It is obvious that calculating $F_{1}(\omega)$ from $G_{1}(\omega)$ would be quite difficult. This complexity increases profoundly for higher order FRFs.

Nevertheless, the analysis has shown that the equilibrium parameters can be estimated directly from the column FRFs. The following useful results were obtained for the low-frequency behaviour of the first three column FRFs [11]:

$$
\lim _{\omega \rightarrow 0}\left|\frac{d G_{1}(\omega)}{d \omega}\right|=\lim _{\omega \rightarrow 0}\left|\frac{\operatorname{Im}\left(G_{1}(\omega)\right)}{\omega}\right|=1+\tilde{a} \frac{1-\varepsilon}{\varepsilon} \frac{Q_{S}}{C_{S}}
$$

$$
\begin{gathered}
\lim _{\omega \rightarrow 0}\left|\frac{d G_{2}(\omega, \omega)}{d \omega}\right|=\lim _{\omega \rightarrow 0}\left|\frac{G_{2}(\omega, \omega)}{\omega}\right|=2|\widetilde{b}| \frac{1-\varepsilon}{\varepsilon} \frac{Q_{S}}{C_{S}} \\
\operatorname{sign}(\tilde{b})=-\operatorname{sign}\left(\lim _{\omega \rightarrow 0}\left(\arg \left(G_{2}(\omega, \omega)\right)\right)\right.
\end{gathered}
$$

$$
\begin{gathered}
\lim _{\omega \rightarrow 0}\left|\frac{d G_{3}(\omega, \omega, \omega)}{d \omega}\right|=\lim _{\omega \rightarrow 0}\left|\frac{G_{3}(\omega, \omega, \omega)}{\omega}\right|=3|\widetilde{c}| \frac{1-\varepsilon}{\varepsilon} \frac{Q_{S}}{C_{S}} \\
\operatorname{sign}(\widetilde{c})=-\operatorname{sign}\left(\lim _{\omega \rightarrow 0}\left(\arg \left(G_{3}(\omega, \omega, \omega)\right)\right)\right.
\end{gathered}
$$

Equations (25-27) can be used for estimation of the equilibrium parameters $\widetilde{a}, \widetilde{b}, \widetilde{c}, \ldots$ (equation (5)) from the low-frequency asymptotes of the FRFs of a chromatographic column. The numerical values of the equilibrium parameters are obtained from the amplitudes and their signs from the phases of the corresponding FRFs. It is important to remind that the sign of the second coefficient of the Taylor series expansion of the isotherm $(\tilde{b})$ determines the shape of the isotherm in the investigated steady-state.

Recently, this analysis has been extended to binary adsorption systems [16]. It was shown that coefficients of competitive adsorption isotherms can be estimated from the low-frequency asymp- 
totes of the FRFs corresponding to the concentrations of both components in the outlet stream from the column. The following Taylor series form of competitive adsorption isotherm expressions was used in this analysis:

$$
\begin{aligned}
q_{i}= & \tilde{a}_{i 1} c_{1}+\tilde{a}_{i 2} c_{2}+\tilde{b}_{i 1} c_{1}^{2}+\tilde{b}_{i 2} c_{2}^{2}+\tilde{b}_{i 3} c_{1} c_{2}+ \\
& +\tilde{c}_{i 1} c_{1}^{3}+\tilde{c}_{i 2} c_{2}^{3}+\tilde{c}_{i 3} c_{1}^{2} c_{2}+\tilde{c}_{i 4} c_{1} c_{2}^{2}+\cdots, i=1,2
\end{aligned}
$$

\section{Experimental verification of the method}

So far, experimental validation of the proposed nonlinear FR methods has been performed only for estimation of single adsorption isotherms from nonlinear FR of a chromatographic column. The experimental investigation is performed using a standard gradient high performance liquid chromatography (HPLC) unit, with an additional 3-way valve and a bypass line. Schematic representation of the used experimental system is given in Fig. 9 The HPLC unit possesses a multi-solvent delivery system, auto sampler with a syringe, thermostated column compartment, UV detector and computer data acquisition station. In order to enable the same pressure during the whole experiment with periodic change of the inlet concentration, a bypass line (long narrow tube) is used. The nonlinear FR method requires measurements of both the inlet and outlet concentration changes during the experiments. This is achieved by switching the 3-way valve in such a way that it changes the direction of the fluid stream leaving the pump section: through the bypass line and than to the detector, for measuring the input concentration change, or through the column and than to the detector, for measuring the output concentration change.

An important issue of practical application of equations (25-27) is to determine the needed frequency range in which asymptotic behaviour of the column FRFs can be assumed. (Using higher frequencies introduces errors in the estimated equilibrium parameters, while using very low frequencies results in very long experiments and large consumption of chemicals.) A straightforward procedure has been developed for proper choice of the input modulation frequency [17]. An important conclusion of this analysis is that it is recommended to work with short columns and high flow-rates [17].

The nonlinear FR method was used for estimation of adsorption isotherms of 4-tert-butyl- phenol and ethyl benzoate, as single solutes, on octadecyl silica, with a mixture of methanol and water $(60: 40, \mathrm{v} / \mathrm{v})$ as solvent. The compounds are chosen based on the fact that these systems exhibit significantly different equilibrium behaviour (adsorption of 4-tert-butylphenol can be described by a simple Langmuir isotherm, while adsorption of ethyl benzoate follows the BET isotherm with an inflection point) [18].

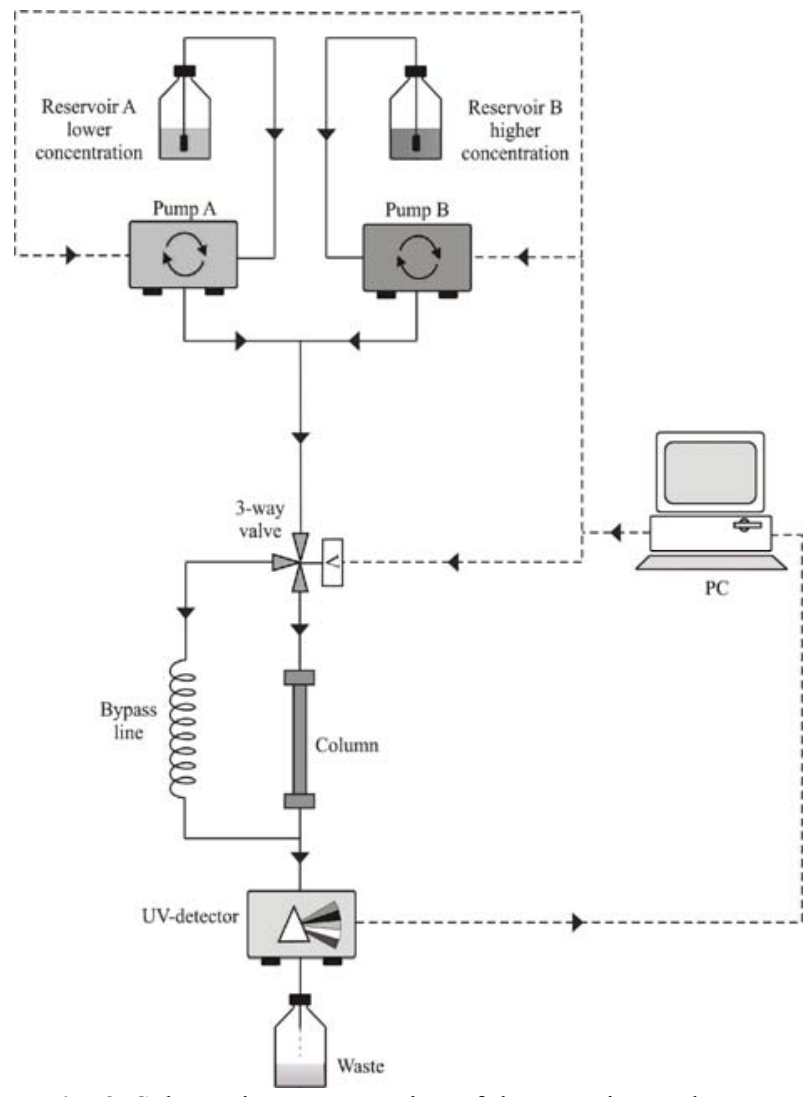

Fig. 9. Schematic representation of the experimental setup for estimation of adsorption isotherms by nonlinear FR of a chromatographic column

The experiments with 4-tert-butylphenol were performed for two steady-state concentrations: 1 and $5 \mathrm{~g} / \mathrm{dm}^{3}$, while the experiments with ethyl benzoate were performed for 3 steady-state concentrations: 5,10 and $13 \mathrm{~g} / \mathrm{dm}^{3}$. For each steadystate point the first three isotherm derivatives were estimated, as explained previously. These data were then used to determine the parameters of the corresponding adsorption isotherms. The results are shown in Figure 10. The isotherms obtained using the nonlinear FR method are shown in parallel with the isotherms obtained by the frontal analysis method, which is used as a standard reference method [15]. The agreement is very good. 


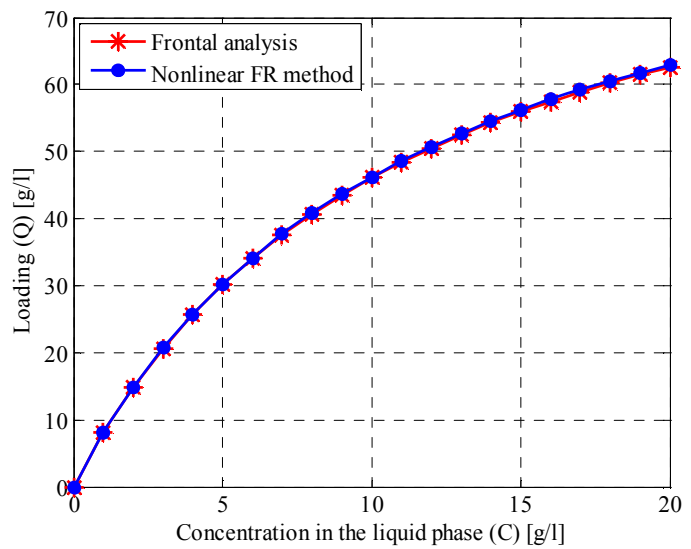

a)

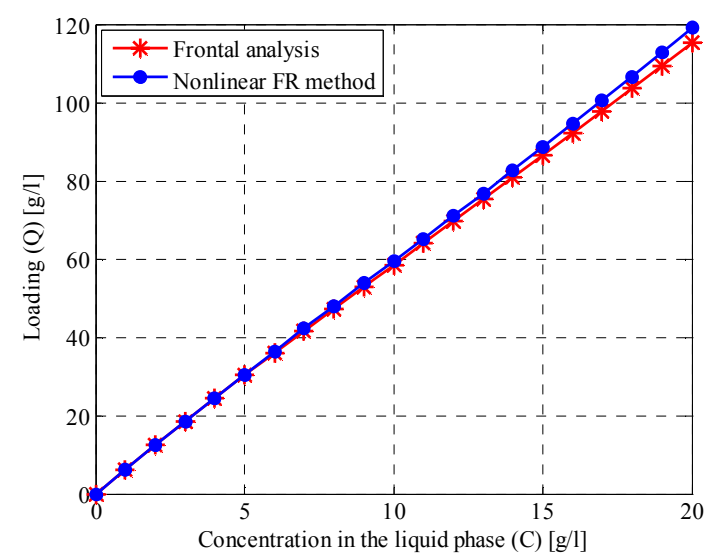

b)

Fig. 10. Experimental adsorption isotherms for 4-tert-butylphenol (left) and ethyl benzoate (right) on octadecyl silica, obtained by nonlinear FR method and frontal analysis

\subsubsection{ZLC system}

The NFR-ZLC method is based on the ZLC apparatus in which the inlet concentration is modulated in a sinusoidal way around a chosen steadystate value. The system is shown schematically in Fig. 11. Owing to a very shallow adsorption bed used, the concentration of the effluent stream is considered equal to the concentration within the bed. This resolves the problem of estimating the particle FRFs from the column ones, which is present when a standard chromatographic column is used, as explained in Section 2.2.2.

The mathematical model of the system shown in Fig. 11, for the case of isothermal conditions and constant flow rate, is given by the following material balance equation:

$$
\frac{d c}{d t}+\beta \frac{d<q>}{d t}=\gamma\left(c_{i n}-c\right), \quad\langle q\rangle=F(c)
$$

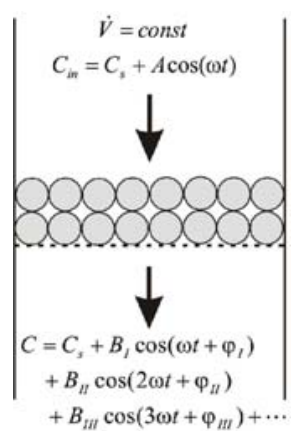

Fig. 11. Schematic picture of the NFR-ZLC system

In Eq. (29) the concentrations in the fluid $c$, and in the particle $q$, as well as the inlet concentration $c_{i n}$, are again defined as nondimensional deviations from their steady-state values and:

$$
\gamma=\frac{\dot{V}}{\varepsilon V}, \quad \beta=\frac{(1-\varepsilon) Q_{S}}{\varepsilon C_{S}}
$$

( $V$ is the volume of the ZLC bed, $\varepsilon$ its porosity and $\dot{V}$ the volumetric flow-rate).

Equation (29) is practically identical to the material balance equation corresponding to the continuous-flow reservoir-type adsorber (equation (13) with $v=0$ ). Accordingly, the ZLC vs. particle FRFs relations are the same as equations (18) to (20).

\subsubsection{Two-reservoir membrane system}

This method is based on investigation of mass transfer through a membrane which separates two chambers (reservoirs) with different partial pressures of the permeating component. An example of such system is shown in Figure 12, where the pressures in both chambers $p_{1}$ and $p_{2}$ are changing periodically, owing to periodic modulation of the volume of reservoir $1\left(V_{1}\right)$. The analysis of the mass transfer through the membrane is based on the measurements of both pressures. This method is developed for investigation of permeation of pure gases for different nonlinear mass transfer mechanisms.

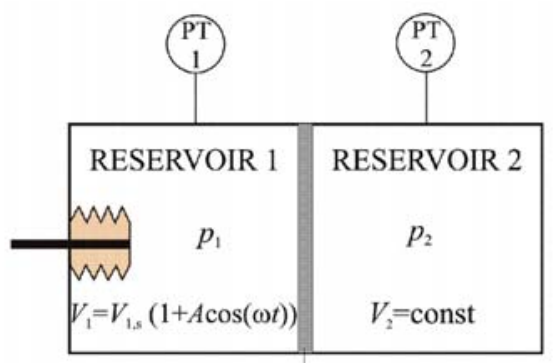

MEMBRANE

Fig. 12. Potential experimental setup for investigation of membrane systems by nonlinear FR 


\section{Generalized membrane permeability}

Classical definition of membrane permeability, based on the following definition of transmembrane flux:

$$
J=P \frac{p_{1}-p_{2}}{L}
$$

is essentially valid only for stationary permeation and linear processes. ( $p_{1}$ and $p_{2}$ are the pressures at two sides of the membrane, $L$ the membrane thickness, $J$ the transmembrane flux and $P$ the permeability.)

Application of the nonlinear FR analysis to transmembrane transport led us to a new, generalized concept of membrane permeability, which can be applied to non-stationary permeation and nonlinear systems. The permeability is defined as a sequence of values (permeabilities of the first, second, third, $\ldots$ order, $\left.P_{I}, P_{I I}, P_{I I I}, \ldots\right)$, defined by the following equation [19]:

$$
\begin{aligned}
<J> & =P_{I} \frac{\Delta p_{1}-\Delta p_{2}}{L}+P_{I I} \frac{\Delta p_{1}^{2}-\Delta p_{2}^{2}}{L}+ \\
& +P_{I I I} \frac{\Delta p_{1}^{3}-\Delta p_{2}^{3}}{L}+\cdots
\end{aligned}
$$

where $\langle J\rangle$ is the mean value of the flux through the membrane in non-stationary conditions and $\Delta p_{1}$ and $\Delta p_{2}$ the changes of the pressures at the leftand right-hand side of the membrane.

The permeabilities $P_{I}, P_{I I}, P_{I I I}, \ldots$ are functions of the equilibrium and kinetic parameters of the membrane, which depend on the membrane transport mechanism. The expressions for $P_{I}$ and $P_{I I}$, corresponding to two common mechanisms of isothermal membrane transport: solution-diffusion and pore-surface diffusion, are given in Table 2.

\section{Table 2}

The permeabilities of the first and second order, for solution-diffusion and pore-surface diffusion mechanisms

\begin{tabular}{lcc}
\hline \hline Mechanism & $P_{I}$ & $P_{I I}$ \\
\hline $\begin{array}{l}\text { Solution- } \\
\text { diffusion }\end{array}$ & $D_{\mu, s} \widetilde{a} \frac{p_{s}}{Q_{s}}$ & $D_{\mu, s} \widetilde{b} \frac{p_{s}^{2}}{Q_{s}}+\frac{D_{\mu}^{(1)} \widetilde{a}^{2} p_{s}^{2}}{2 Q_{s}}$ \\
$\begin{array}{l}\text { Pore-surface } \\
\text { diffusion }\end{array}$ & $D_{e f f} \widetilde{a}_{e f f} \frac{p_{s}}{Q_{s}}$ & $(1-\varepsilon)\left(D_{s, s} \widetilde{b} \frac{p_{s}^{2}}{Q_{s}}+\frac{D_{s}^{(1)} \widetilde{a}^{2} p_{s}^{2}}{2 Q_{s}^{2}}\right)$ \\
\hline \hline
\end{tabular}

The model equations for these two mechanisms are practically identical to the model equations for micropore and pore-surface diffusion mechanisms of adsorption. In the analysis of membrane transport, the concentration dependence of the micropore and surface diffusion coefficients were taken into account, using expressions analogous to equation (10).

\section{Definition of the FRFs}

Several sets of FRFs can be defined for this system. The most informative is the one correlating the changes of the pressures in Reservoirs 2 and $1\left(\Delta p_{2}\right.$ and $\left.\Delta p_{1}\right)$.

The shapes of the first and second order functions (denoted as $Z_{1}$ and $Z_{2}$ ) are presented in Fig. 13 for the solution-diffusion model and in Fig. 14 for the pore-surface diffusion model.

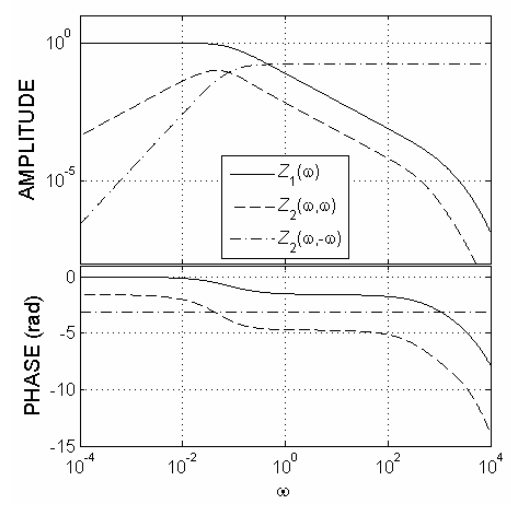

Fig 13. First and second order FRFs for solution-diffusion model

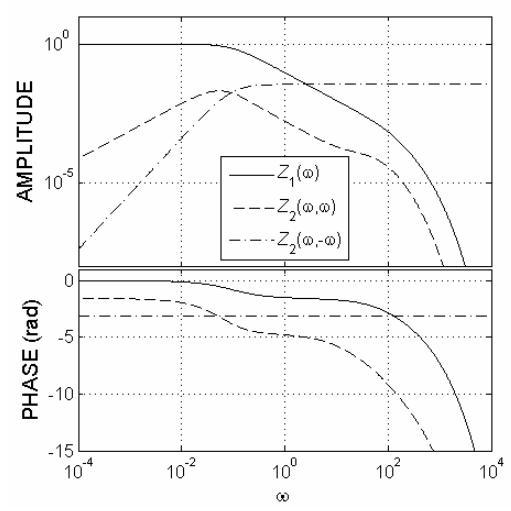

Fig 14. First and second order FRFs for pore-surface diffusion model

Inspection of these two figures shows differences in the shapes of the second order functions $Z_{2}(\omega, \omega)$ corresponding to the two models. 


\section{Estimation of the first and second order permeabilities}

In Fig. 15 we show the imaginary parts of the first order functions $Z_{1}(\omega)$ for the solutiondiffusion and pore-surface diffusion models. The curves corresponding to the two models overlap. This was achieved by using nondimensional frequency on the abscisa, defined as a ratio of the dimensional frequency and a characteristic frequency $\omega^{*}$.

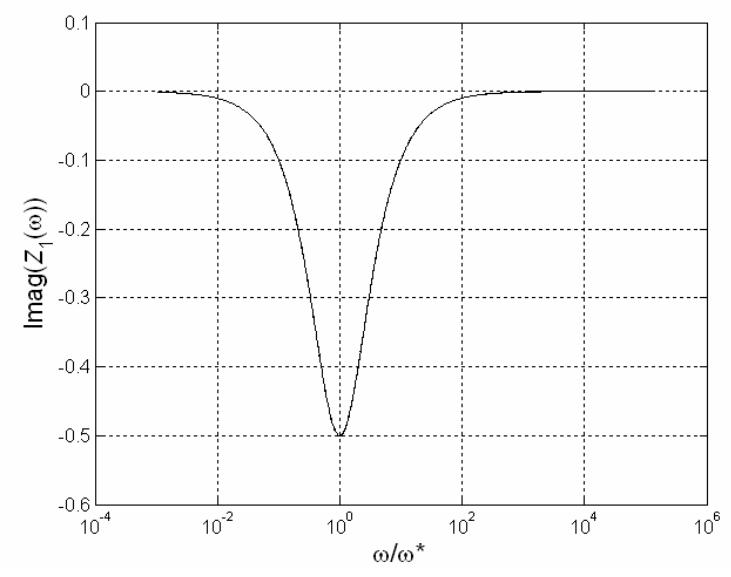

Fig. 15. Imaginary part of $Z_{1}(\omega)$

The definitions of the characteristic frequencies are:

- For the solution-diffusion mechanism:

$$
\omega^{*}=\frac{D_{\mu, s} \widetilde{a}_{p} S}{L V_{2}} \frac{Q_{S}}{C_{S}}
$$

- For the pore-surface mechanism

$$
\omega^{*}=\frac{D_{e f f} \tilde{a}_{p, e f f} S}{L V_{2}} \frac{Q_{S}}{C_{S}}
$$

In (33) and (34) $L$ is the membrane thickness, $S$ membrane surface area and $V_{2}$ volume of the constant volume reservoir.

As it can be seen from Fig. 15, the minimum of the function $\operatorname{Imag}\left(Z_{1}(\omega)\right)$ is obtained for $\omega=\omega^{*}$.

By combining the expressions defining $\omega^{*}$ in (33) and (34) and the definitions of the first order permeability $P_{I}$ given in Table 2 , the following common expression was derived:

$$
P_{I}=\frac{V_{2} L}{S R_{g} T} \omega^{*}
$$

It should be noted that the characteristic frequency $\omega^{*}$ depends not only on the equilibrium and transport parameters of the investigated membrane, but also on the geometry of the experimental system, i.e. on the ratio of the membrane surface area $S$ and the volume of the reservoir $V_{2}$. Consecutively, by choosing the right geometry it would be possible to adjust the frequency range of interest so that it can be experimentally feasible.

The second order permeability $P_{I I}$ can be estimated from the second order $Z$-functions. The simplest way to do that is to use the following expression:

$$
\lim _{\omega \rightarrow \infty} Z_{2}(\omega,-\omega)=\frac{P_{I I}}{P_{I}} p_{s}
$$

which is valid for both models. With the first order permeability $P_{I}$ estimated from the first order FRF $Z_{1}(\omega)$, equation (36) enables direct estimation of the second order permeability $P_{I I}$ corresponding to the steady-state pressure $p_{s}$.

Based on the estimated first and second order permeability, it is possible to determine the basic equilibrium and kinetic parameters of the corresponding transmembrane mass transport mechanism.

Recently we started nonlinear FR analysis of mass transport through porous membranes for binary mixtures of inert and adsorbable components [20].

\section{COMPUTATIONAL TECHNIQUE FOR FAST ESTIMATION OF PERIODIC STEADY-STATES}

Industrial adsorption processes are usually performed in fixed-beds, which need to be operated in a cyclic way, with adsorption and desorption (regeneration) steps. A number of different cyclic adsorption processes have been developed in the last 30 years (e.g. TSA, PSA and SMB). Computational simulations of these cyclic processes, which are often used as an aid in their analysis and optimization, usually demand long and tedious numerical solutions of sets of partial differential model equations, with occasional convergence problems.

Based on Fourier and Volterra series expansions and the concept of higher order frequency response functions, we have developed a new method for fast approximate calculation of the cyclic steady states of periodic processes, which avoids long numerical solutions of the model equa- 
tions. The system input is represented in the form of Fourier series, while the output is presented in the form of Volterra series. For practical applications, both the input and the output series are approximated by finite length sums. On the other hand, the nonlinear model is replaced by a finite set of FRFs, derived from it. In this way, the approximate periodic quasi-steady state of the system output is calculated directly, using only complex algebra.

\subsection{Basic concept and procedures}

In principle, periodic operation of any process is performed by periodic modulation of one or more input variables. If the process is nonlinear, sets of higher order FRFs need to be defined for its proper mathematical description. A block diagram of a nonlinear system with two inputs $(x$ and $z$ ) and one output $(y)$ is presented in Fig. 16.

As shown in Fig. 16, three sets of FRFs are needed to describe such a system: two of them relating the output to each of the inputs and one set of cross-functions.

It is well known that any periodic function can be represented as an indefinite sum of simple harmonic functions, i.e. in the Fourier series form. Accordingly, the input functions $x$ and $z$ can be written in the following way:

$$
\begin{gathered}
x(\tau)=\sum_{k=-\infty}^{\infty} \frac{1}{2} A_{k} e^{j w_{k} \tau} \quad \begin{array}{c}
\text { with the } n \text {-th elements of these series defined in } \\
\text { the following way: }
\end{array} \\
z(\tau)=\sum_{k=-\infty}^{\infty} \frac{1}{2} B_{k} e^{j u_{k} \tau} \quad(38) \quad \sum_{x, n}(\tau)=\frac{1}{2^{n}} \sum_{k_{1}=-\infty}^{\infty} \sum_{k_{2}=-\infty}^{\infty} \cdots \sum_{k_{n}=-\infty}^{\infty} A_{k_{1}} A_{k_{2}} \cdots A_{k_{n}} G_{n, x^{n}}\left(w_{k_{1}}, w_{k_{2}}, \cdots, w_{k_{n}}\right) e^{j\left(w_{k_{1}}+w_{k_{2}}+\cdots+w_{k_{n}}\right) \tau} \\
y_{x z, n}(\tau)=\frac{1}{2^{n}} \sum_{m=1}^{n-m} \sum_{k_{1}=-\infty}^{\infty} \sum_{k_{n}=-\infty}^{\infty} A_{k_{1}} \cdots A_{k_{m}} B_{k_{m+1}} \cdots B_{k_{n}} G_{n, x^{m} z^{n-m}}\left(w_{k_{1}}, \cdots, w_{k_{m}}, u_{k_{m+1}}, \cdots, u_{k_{n}}\right) e^{j\left(w_{k_{1}}+\cdots+w_{k_{m}}+u_{k_{m+1}}+\cdots+u_{k_{n}}\right) \tau} \\
\sum_{k_{1}=-\infty}^{\infty} \sum_{k_{2}=-\infty}^{\infty} \sum_{k_{n}=-\infty}^{\infty} B_{k_{1}} B_{k_{2}} \cdots B_{k_{n}} G_{n, z^{n}}\left(u_{k_{1}}, u_{k_{2}}, \cdots, u_{k_{n}}\right) e^{j\left(u_{k_{1}}+u_{k_{2}}+\cdots+u_{k_{n}}\right) \tau}
\end{gathered}
$$

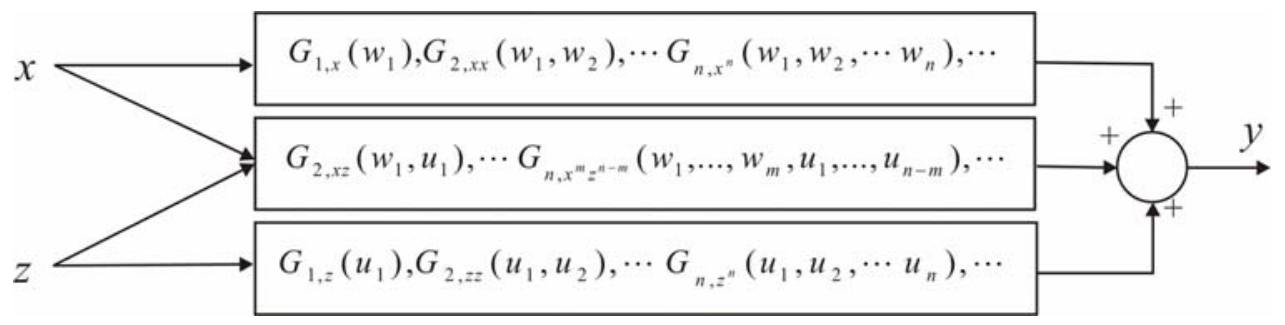

where:

$$
\begin{aligned}
& A_{-k}=\operatorname{conj}\left(A_{k}\right), \\
& B_{-k}=\operatorname{conj}\left(B_{k}\right), \\
& w_{k}=k w_{1}, u_{k}=k u_{1},
\end{aligned}
$$

while $w_{1}$ and $u_{1}$ are the basic frequencies of the input changes $x$ and $z$, respectively. The magnitudes of $A_{\mathrm{k}}$ and $B_{\mathrm{k}}$ are the amplitudes and their phase angles the phases of the harmonics of the corresponding frequencies $w_{k}$ and $u_{k}$ of the inputs $x$ and $z$, respectively.

For the case of two periodic inputs, the periodic quasi-steady state of the output can be represented as a sum of three terms, each of them corresponding to the contribution of each set of HFRFs, presented in Figure 16:

$$
y(\tau)=y_{x}(\tau)+y_{z}(\tau)+y_{x z}(\tau)
$$

Each of these three terms can be represented by an indefinite Volterra series:

$$
\begin{aligned}
& y_{x}(\tau)=\sum_{n=1}^{\infty} y_{x, n}(\tau) \\
& y_{z}(\tau)=\sum_{n=1}^{\infty} y_{z, n}(\tau) \\
& y_{x z}(\tau)=\sum_{n=1}^{\infty} y_{x z, n}(\tau)
\end{aligned}
$$

Fig. 16. A block diagram of a nonlinear system with two inputs and one output 
The Volterra series, given by equations ( 40 45), with indefinite sums, represent the periodic quasi-stationary state of the output exactly. In practice, only finite sums can be calculated, resulting with equations corresponding to approximate solution of the periodic output. For practical applications the inputs are approximated by finite sums of only the first $K$ harmonics, while the output is approximated by the sum of only the first $N$ elements of the Volterra series.

The quality of the approximate solution obtained in this way, i.e. its closeness to the exact solution, increases with the increase of both $K$ and $N$.

Based on this analysis, the following procedure for approximate calculation of the quasisteady states of periodic processes is defined:

Step 1: Postulating an appropriate mathematical model for the investigated process.

Step 2: Deriving the FRFs up to the $N$-th order, based on the postulated model.

Step 3: Defining periodic input or inputs and their approximation by finite sums, taking into account only the first $K$ harmonics.

Step 4: Calculating the approximate output. In this procedure, the most complex and time consuming step is derivation of the FRFs (step 2). Nevertheless, this step has to be performed only once for each investigated system. Once derived, these functions can be used for any shapes of the periodic input changes and for any set of model parameters.

Steps 3 and 4, naturally, have to be repeated for each particular simulation. Step 3 can be easily performed by applying the Fourier transform to the periodic input functions, while the last step, calculation of the periodic output in its quasi-steady state, is practically reduced to simple algebra.

\subsection{Example: Cyclic operation of an adsorption column}

In order to illustrate the presented procedure and our new method, we applied it to simulation of cyclic operation of an adsorption column with periodic modulation of the inlet concentration or/and temperature of the entire adsorbent bed [3].

Three cases of periodic operation of the adsorption column were analyzed:

Case 1: Periodic modulation of the inlet concentration and constant temperature of the adsorbent bed;Periodic modulation of the temperature of the adsolrbent bed and constant inlet concentration;
Case 3: Simultaneous periodic modulations of the inlet concentration and the temperature of the adsorbent bed.

The cyclic operation of an adsorption column was simulated based on the equilibrium-dispersive model, with equilibrium relation between the concentration in the solid phase $q$ on one, and concentration in the fluid phase $c$ and temperature $\theta$, on the other hand, given in the Taylor series form:

$$
\begin{aligned}
q= & \widetilde{a}_{c} c+\widetilde{a}_{\theta} \theta+\widetilde{b}_{c c} c^{2}+\widetilde{b}_{\theta \theta} \theta^{2}+\widetilde{b}_{c \theta} c \theta+ \\
& +\widetilde{c}_{c c c} c^{3}+\widetilde{c}_{\theta \theta \theta} \theta^{3}+\widetilde{c}_{c c} c^{2} \theta+\widetilde{c}_{c \theta \theta} c \theta^{2}+\cdots
\end{aligned}
$$

The model assumes local equilibrium and uniform temperature within the column.

Starting from this model, three series of FRFs: $G_{c}-$ (relating the outlet and inlet concentration changes), $G_{\theta}$-(relating the outlet concentration and column temperature) and $G_{c \theta}$ - functions (the cross-functions) were derived, up to the third order. Typical forms of these functions are shown in Figures 17, 18 and 19, respectively, in the form of standard Bode plots.

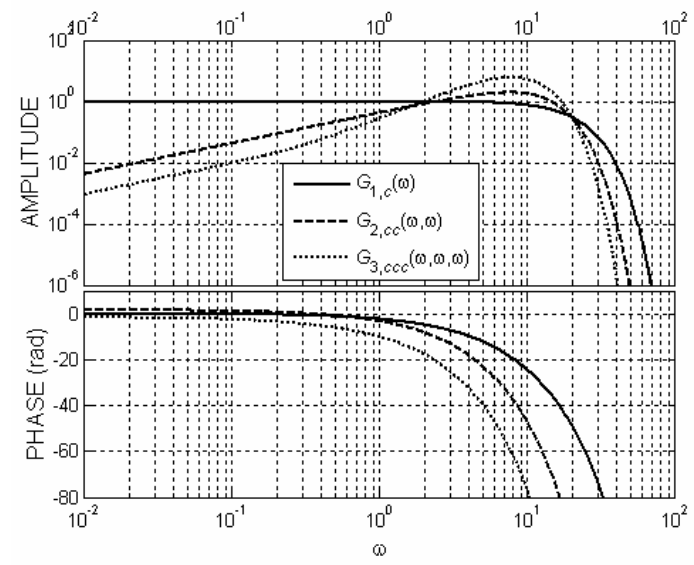

Fig. 17. Typical $G_{c}$-functions

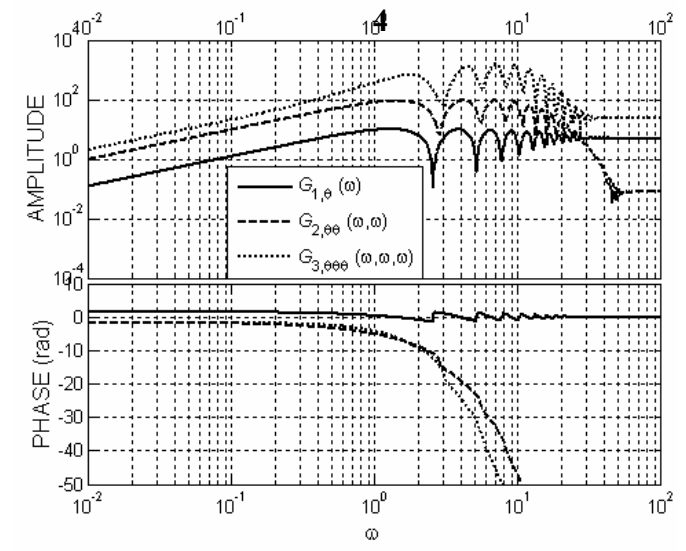

Fig. 18. Typical $G_{\theta}$-functions 


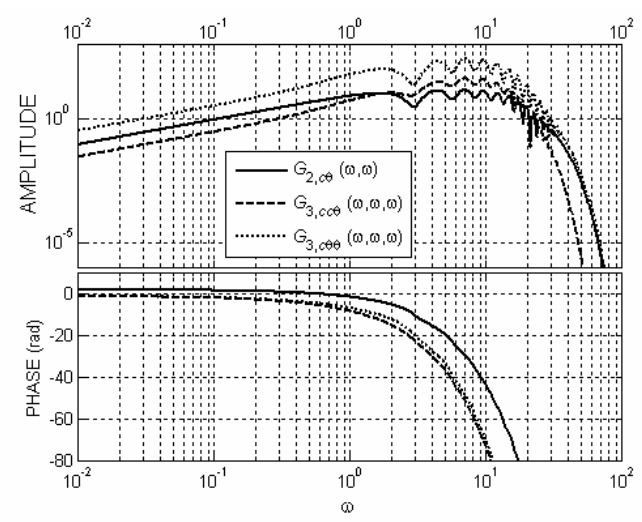

Fig. 19. Typical $G_{c \theta}$-functions

The derived functions were used for direct calculation of the outlet concentration for defined periodic modulation of the inlet concentration or/and column temperature. Two types of modulation functions were considered: sinusoidal and rectangular. All calculations were performed in the complex domain.

One set of results is shown in Figure 20. They correspond to simultaneous out-of-phase sinusoidal
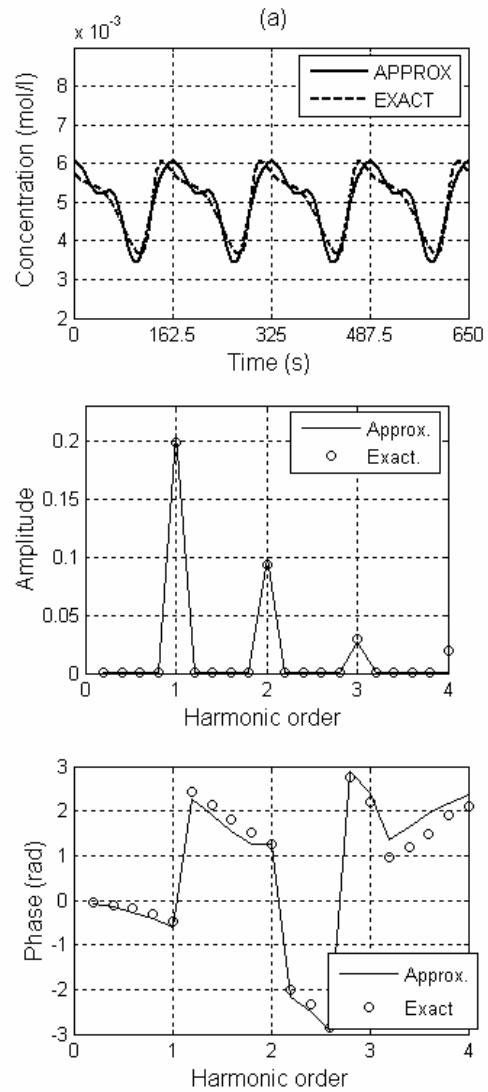

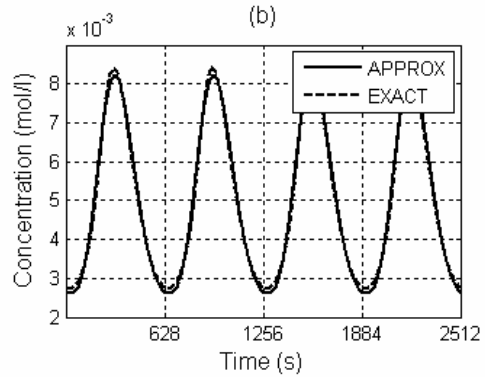

modulation of the inlet concentration and column temperatures. The results corresponding to two modulation frequencies are shown: the lower value corresponding to very significant nonlinear effects and the higher corresponding to weaker nonlinearity. Along with the temporal change of the outlet concentration, the Fourier spectra (amplitudes and phases) of the output are also shown, as they offer very good insight in the contribution of the higher harmonics. For comparison, along with the approximate outlet concentration calculated based on the first three FRFs, we also provide the numerical solution of the model equations, which is assumed to be exact. More results, for modulation of only one input and for rectangular input changes can be found in Ref. 3.]

The results presented in Fig. 20 show very good agreement between the approximate (based on the first three FRFs) and exact (numerical) solution of the adsorption column quasi-steady state response. Introducing the fourth and higher order FRFs into the approximate solution would further improve its quality.
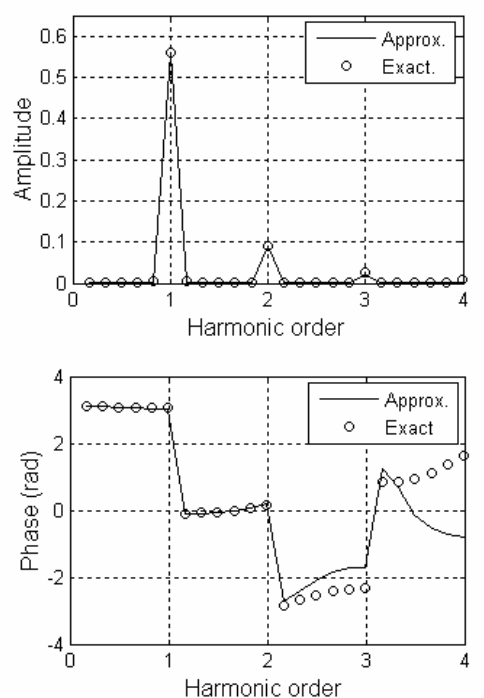

Fig. 20. Outlet concentrations and their Fourier spectra for simultaneous, out-of-phase sinusoidal changes of the inlet concentration $(25 \%)$ and adsorbent temperature $(3.2 \%)-$ Case $3:$ a) period $=162.5 \mathrm{~s}, \mathrm{~b})$ period $=628 \mathrm{~s}$ 


\section{CONCLUSIONS}

The purpose of this manuscript is to show the potentials of using nonlinear frequency response analysis and the concept of higher order frequency response functions for investigating adsorption systems. The two directions of this application shown here have two completely different aims:

The first one, presented in Section 2, should contribute to the development of new methods for investigation of adsorption equilibrium and kinetics. The main advantages of using the nonlinear FR techniques are that they have good potential regarding mechanism discrimination and estimation of both equilibrium and kinetic parameters. Different experimental arrangements can be used, as shown in Section 2.2, and each of them has its advantages and disadvantages. For practical application of the presented methods, all these advantages and disadvantages have to be analyzed, together with some additional aspects, such as definition of the optimal frequency range of the input modulations and the possibility to produce them physically, the best choice of input amplitudes and so on. Nevertheless, we believe that these methods have good potential and bright future.

The second direction, presented in Section 3, gives an easy and elegant method to predict the periodic behaviour of different cyclic processes, using only analytical mathematical tools and avoiding long and tedious numerical solutions and all the convergence problems associated with them. We believe that it can be very useful for many researchers and practitioners working on adsorption and in the chemical engineering field, in general.

Acknowledgment: This work was supported by the Serbian Ministry of Science in the frame of Project No. 142014.

\section{REFERENCES}

[1] D. D. Weiner and J. F. Spina, Sinusoidal analysis and modelling of weakly nonlinear systems, Van Nostrand Reinhold, New York, 1980.

[2] Petkovska, M., Nonlinear Frequency Response Method for Investigation of Equilibria and Kinetics in Adsorption Systems, in Finely Dispersed Particles: Micro, Nano- and Atto-Engineering, A. M. Spasic and J. P. Hsu (Ed.), pp. 283-327, CRC Taylor \& Francis, Boca Raton, 2006.

[3] M. Petkovska and A. Marković, Fast Estimation of QuasiSteady States of Cyclic Nonlinear Processes Based on Higher-Order Frequency Response Functions. Case Study: Cyclic Operation of an Adsorption Column, Ind. Eng. Chem. Res.. 45, 266-291 (2006).
[4] M. Petkovska, Nonlinear Frequency Response of Nonisothermal Adsorption Controlled by Micropore Diffusion with Variable Diffusivity, J. Serb. Chem. Soc., 65, 939 961 (2000).

[5] M. Petkovska, Nonlinear Frequency Response of Nonisothermal Adsorption Systems, Nonlinear Dynamics, 26, 351-370 (2001).

[6] M. Petkovska M. and D. D. Do, Use of higher order FRFs for identification of nonlinear adsorption kinetics: single mechanisms under isothermal conditions, Nonlinear Dynamics, 21, 353-376 (2000).

[7] M. Petkovska and L. T. Petkovska, Use of Nonlinear Frequency Response for Discriminating Adsorption Kinetics Mechanisms Resulting with Bimodal Characteristic Functions, Adsorption, 9, 133-142 (2003).

[8] M. Petkovska, Application of Nonlinear Frequency Response to Adsorption Systems with Complex Kinetic Mechanisms, Adsorption, 11, 492-502 (2005).

[9] L. Song and L. V. C. Rees, Adsorption and Transport of n-Hexane in Silicalite-1 by Frequency Response Technique, J. Chem. Soc. Faraday Trans. 93, 649-657 (1997).

[10] D. D. Do, Chem. Eng. Sci. Hierarchy of Rate Models for Adsorption and Desorption in Bidispersed Structured Sorbents, 45, 1373-1381 (1990).

[11] M. Petkovska and A. Seidel-Morgenstern, Nonlinear frequency response of a chromatographic column. Part I: Application to estimation of adsorption isotherms with inflection points, Chem. Eng. Commun. 192, 1300-1333 (2005).

[12] M. Ilić, M. Petkovska, and A. Seidel-Morgenstern, Nonlinear frequency response method for estimation of single solute adsorption isotherms. Part II. Experimental study, Chem. Eng. Sci., 62, 4394-4408 (2007).

[13] Y. Yasuda, Determination of vapor diffusion coefficients in zeolite by the frequency response method, J. Phys. Chem., 86, 1913-1917 (1982).

[14] M. Petkovska and D. D. Do, Nonlinear frequency response of adsorption systems: Isothermal batch and continuous flow adsorber, Chem. Eng. Sci., 53, 3081-3097 (1998).

[15] G. Guiochon, S. G. Shirazi and A. M. Katti, Fundamentals of Preparative and Nonlinear Chromatography, Academic Press, London, 1994.

[16] M. Ilić, M. Petkovska, and A. Seidel-Morgenstern, Theoretical investigation of the adsorption of a binary mixture in a chromatographic column using the nonlinear frequency response technique, Adsorption, 13, 541-567 (2007).

[17] M. Ilić, M. Petkovska, and A. Seidel-Morgenstern, Nonlinear frequency response functions of a chromatographic column - A critical evaluation of their potential for estimation of single solute adsorption isotherms, Chem. Eng. Sci., 62, 1269-1281 (2007).

[18] F. Gritti, G. Guiochon, Band splitting in overloaded isocratic elution chromatography, II. New competitive adsorption isotherms, Journal of Chromatography, A, 1008, 23-41 (2003).

[19] M. Petkovska, Lj. T. Petkovska, Application of Nonlinear Frequency Response to Investigation of Membrane Transport, Separation Science and Technology, 41, 43-72 (2006).

[20] M. Lazar, Razvoj metode za ispitivanje permeacije binarnih gasnih smeša kroz membrane od poroznog stakla zasnovane na analizi nelinearnog frekventnog odziva teorijska analiza, Diploma thesis (in Serbian), University of Belgrade, Belgrade, 2008. 